\title{
Identification of Protein Kinase C Isoforms Involved in Type 1 Diabetic Encephalopathy in Mice
}

\author{
Jiayin Zheng $\mathbb{D}^{1},{ }^{1}$ Yue Wang, ${ }^{2}$ Song Han, ${ }^{1}$ Yanlin Luo, ${ }^{1}$ Xiuli Sun, ${ }^{1}$ Ning Zhu, ${ }^{1}$ Li Zhao $\mathbb{D},{ }^{1}$ \\ and Junfa $\operatorname{Li} \mathbb{D}^{1}$ \\ ${ }^{1}$ Department of Neurobiology and Center of Stroke, Beijing Institute for Brain Disorders, Capital Medical University, \\ Beijing 100069, China \\ ${ }^{2}$ Department of Neurology, Beijing Chaoyang Hospital, Capital Medical University, Beijing, China
}

Correspondence should be addressed to Li Zhao; zhaoli@ccmu.edu.cn and Junfa Li; junfali@ccmu.edu.cn

Received 27 September 2017; Accepted 23 January 2018; Published 18 March 2018

Academic Editor: Munmun Chattopadhyay

Copyright (C) 2018 Jiayin Zheng et al. This is an open access article distributed under the Creative Commons Attribution License, which permits unrestricted use, distribution, and reproduction in any medium, provided the original work is properly cited.

\begin{abstract}
Diabetic encephalopathy is a complication of diabetes mellitus characterized by impaired cognitive functions. Protein kinase C (PKC) isoforms are rarely reported on diabetic encephalopathy, although they have been believed to play crucial roles in other diabetic complications. In this study, streptozotocin- (STZ-) induced diabetic mice were found to exhibit learning and memory deficits in the Morris water maze test. Meanwhile, the expression of $\mathrm{cPKC} \beta \mathrm{II}, \mathrm{nPKC} \varepsilon$, and $\mathrm{cPKC} \gamma$ did not change in the hippocampus, cortex, and striatum at 2 and 8 weeks after STZ injection. The $\mathrm{nPKC} \varepsilon$ translocation to the membrane, where it is activated, was not altered in the above brain regions at 2 and 8 weeks after STZ injection. Nevertheless, cPKC $\beta \mathrm{II}$ translocation to the membrane was significantly decreased in the cortex and hippocampus at 8 weeks after STZ injection. The translocation of cPKC $\gamma$ from the cytosol to the membrane was remarkably decreased in the hippocampus at 2 and 8 weeks and in the cortex and striatum at 8 weeks after STZ injection. In addition, deletion of $\mathrm{cPKC} \gamma$ aggravated the impairment of spatial learning and memory. In conclusion, our results suggest that the decrease in the activity of $\mathrm{cPKC} \beta \mathrm{II}$ and $\mathrm{cPKC} \gamma$, especially $\mathrm{cPKC} \gamma$, may play key roles in the pathogenesis of diabetic encephalopathy.
\end{abstract}

\section{Introduction}

The prevalence rates of diabetes mellitus (DM) have increased rapidly over the past three decades in the world [1]. Some clinical studies have shown that high blood glucose increases the risk of Alzheimer's disease (AD) [2-4]. It has been manifested that type 1 diabetes mellitus (T1DM) has shown neurofibrillary and senile plaque, two major pathologic characteristics of $\mathrm{AD}$, in the animal models $[5,6]$. To describe cognitive impairment in diabetes, the term "diabetic encephalopathy" was introduced [7]. Now, diabetic encephalopathy is accepted as one of the most widespread diabetic complications in the central nervous system [8]. Because of a lack of effective treatment for diabetic encephalopathy, much interest now is focused on its molecular mechanism.

Constant hyperglycemia inside the cell increases the synthesis of diacylglycerol, which is one of the critical activating factors for protein kinase C (PKC) [9]. PKC, a family of Ser/Thr kinases that regulate a series of cellular processes, may play a key role in diabetes and its complications. According to the forms of activation, PKC isoforms are included in three groups: (1) conventional PKC isoforms $(\mathrm{cPKC} \alpha, \beta \mathrm{I}, \beta \mathrm{II}$, and $\gamma)$ are activated by diacylglycerol, phosphatidylserine, and $\mathrm{Ca}^{2+}$ influx; (2) novel PKC isoforms (nPKC $\delta, \varepsilon, \eta$, and $\theta$ ) require diacylglycerol; and (3) atypical $\mathrm{PKC}$ isoforms (aPKC $\zeta$ and $\iota / \lambda)$ do not bind either second messengers. It has been demonstrated that the $\mathrm{cPKC} \beta \mathrm{II}$, ${ }_{\mathrm{CPKC}} \gamma$, and $\mathrm{nPKC} \varepsilon$, widely expressed in the nervous system, participate in many diabetic complications [10-14].

cPKC $\beta I$ is the most studied isoform for diabetic complications. Deletion or inhibition of the $\mathrm{CPKC} \beta \mathrm{II}$ can reduce glomerular, albuminuria, and mesangial expansion, which prevent the thickening of the glomerular basement membrane and the obliteration of glomerular capillaries in a 
diabetic kidney $[15,16]$. The cPKC $\beta$ II inhibitor can reverse acute blood glucose fluctuation-induced endothelial cell apoptosis increase, inflammatory cytokine level increase, and insulin signaling impairment, indicating that PKC $\beta \mathrm{II}$ may serve as a target for anticardiovascular diseases [11]. The $\mathrm{PPKC} \beta \mathrm{II}$ inhibitor can also reduce the incidence of visual loss and prevent blood-retinal barrier breakdown in diabetic patients and animal models [17].

$\mathrm{nPKC} \varepsilon$ is highly relative to insulin resistance. The key role of $\mathrm{nPKC} \varepsilon$ for fat-induced hepatic insulin resistance is demonstrated with antisense oligonucleotide-mediated knockdown of $\mathrm{nPKC} \varepsilon$ in high-fat feeding rats [18]. Several studies in type 2 diabetic patients have demonstrated that activation of $\mathrm{nPKC} \varepsilon$ by hepatic accumulation of the diacylglycerol can result in hepatic insulin resistance and nonalcoholic fatty liver disease [19]. nPKCe deletion also enhances the amplifying pathways of glucose-stimulated insulin secretion and lipolysis in diabetic mouse beta-cells [20].

Compared to other PKC isoforms, $\mathrm{PPKC} \gamma$ is located only in the neurons of the central nervous system. Some studies have reported that the inhibitors of $\mathrm{cPKC} \gamma$ could reverse the DM-associated chronic impairment of neurovascular coupling [10]. The increase in $\mathrm{CPKC} \gamma$ expression in a trigeminal spinal nucleus is associated with orofacial thermal hyperalgesia in diabetic mice [21]. The increase in $\mathrm{cPKC} \gamma$ activity is also associated with diabetic embryonic dysmorphogenesis in rat [22]. However, few studies investigate the roles of the three specific PKC isoforms in the diabetic encephalopathy. In this study, we explored whether $\mathrm{cPKC} \beta \mathrm{II}, \mathrm{cPKC} \gamma$, and $\mathrm{nPKC} \varepsilon$ participated in the pathogenesis of type 1 diabetic encephalopathy induced by streptozocin (STZ) injection in mice.

\section{Materials and Methods}

2.1. Animals. C57BL/6 wild-type and cPKC $\gamma$ knockout mice (male, 18-22g) were purchased from Jackson Laboratory (Bar Harbor, Maine 04609, USA). Mice were housed, three per cage. The mice with free access to water and food were maintained in the Experimental Animal Center of Capital Medical University, the People's Republic of China. The experimental procedures were approved by the experimental animal ethics committee of Capital Medical University (permit number AEEI-2014-035) and conducted according to the recommendations in the Guide for the Care and Use of Laboratory Animals of the National Institutes of Health.

2.2. Induction of Type 1 Diabetes Mellitus in Mice. Animals were randomly divided into three groups, namely, the CON group (with citrate buffer treatment), T1DM group (with STZ treatment), and T1DM + cPKC $\gamma$ group (cPKC $\gamma$ knockout mice with STZ treatment). Following an overnight fast, T1DM mice were induced by low doses of freshly prepared STZ $(50 \mathrm{mg} / \mathrm{kg} /$ day, i.p.), dissolved in a $0.1 \mathrm{M}$ citrate buffer ( $\mathrm{pH} 4.5$ ), over five consecutive days. The control mice were only injected with citrate buffer $(5 \mathrm{~mL} / \mathrm{kg} /$ day, i.p.). The fasting blood glucose level was measured every week using a blood sample from the tail vein with the aid of a
OneTouch ${ }^{\circledR}$ Ultra blood glucose meter (Milpitas, CA, USA). Mice with blood glucose levels over $11.1 \mathrm{mmol} / \mathrm{L}$ were considered diabetic and used for the study [23]. At 2 weeks and 8 weeks after STZ injection, the hippocampus, prefrontal cortex, and striatum of the mice in the CON and T1DM groups were prepared for the determination of $\mathrm{PKC}$ isoform expression levels and membrane translocation of $\mathrm{PKC}$ isoforms ( $n=6$ per group, resp.). At 8 weeks after STZ injection, the mice in the CON, T1DM, and T1DM + cPKC $\gamma$ groups were tested in the Morris water maze $(n=12$ per group, resp.).

2.3. Cytosolic and Membrane Fractions and Whole Tissue Homogenate Preparation. As previously reported [24], the dissected samples were first homogenized at $4^{\circ} \mathrm{C}$ in buffer A [50 mM Tris-Cl, pH 7.5, containing $1 \mathrm{mM}$ DTT, $2 \mathrm{mM}$ EDTA, $2 \mathrm{mM}$ EGTA, $50 \mathrm{mM}$ potassium fluoride (KF), $5 \mathrm{mM}$ sodium pyrophosphate, and a protease inhibitor mixture]. Homogenates were centrifuged at $30,000 \mathrm{~g}$ for $30 \mathrm{~min}$, and the supernatant was collected as cytosolic fractions. The pellet fractions (membrane fractions) were resuspended in buffer A containing 2\% SDS before being sonicated and centrifuged again. These two fractions were analyzed for membrane translocation of PKC isoforms. To analyze PKC isoform expression, the whole tissue was homogenized and sonicated in RIPA buffer. The concentration of protein was analyzed as previously reported [25].

2.4. Western Blot. As previously reported [26], the samples $(30 \mu \mathrm{g})$ were subjected to $10 \%$ SDS-PAGE and transferred onto polyvinylidene difluoride membrane (GE Healthcare, $\mathrm{UK})$; the membrane was blocked with $10 \%$ nonfat milk for $1 \mathrm{~h}$ and probed with anti-cPKC $\beta \mathrm{II}$ (number sc-210, Santa Cruz Biotechnology, Santa Cruz, USA), cPKC $\gamma$ (number sc211, Santa Cruz Biotechnology, Santa Cruz, USA), and nPKC $\varepsilon$ (number sc-214, Santa Cruz Biotechnology, Santa Cruz, USA). The horseradish peroxidase-conjugated goat antirabbit (number 31460, ThermoFisher Scientific, Rockford, USA) and anti-mouse IgG (number 31430, ThermoFisher Scientific, Rockford, USA) were used as second antibodies at a 1:4000 dilution for $1 \mathrm{~h}$ at room temperature. Signals were visualized via an enhanced chemiluminescent reagent solution (chemiluminescent HRP substrate, Millipore Corporation, USA). To verify the equal loading of protein, the blots were reprobed with primary monoclonal antibodies against $\beta$-actin (number 60008-1-lg, Proteintech, Rosemont, USA) or $\mathrm{Na}^{+} / \mathrm{K}^{+}$ATPase (number 14418-1-AP, Proteintech, Rosemont, USA). The protein expression levels of PKC isoforms were calculated as $100 \%$ in the control group, and then the other groups were expressed as the percentage of the control group. Quantitative analysis for immunoblotting was done by Fusion Capt 16.15 software (Fusion FX6 XT, Vilber Lourmat, France).

2.5. Morris Water Maze. At 8 weeks after STZ injection, spatial learning and memory were tested by the Morris water maze. Briefly, a custom-built water tank $(122 \mathrm{~cm}$ diameter, $50 \mathrm{~cm}$ height) with a white nonreflective interior surface was filled with opaque water $\left(19-22^{\circ} \mathrm{C}\right)$ containing nontoxic 
titanium white-colored dye. The experiment was performed in a room with low-light indirect lighting. Four different extramaze cues were fixed at four quartiles of the tank periphery (Figure 1(e)). In the target quadrant (quadrant II), a platform was submerged $1 \mathrm{~cm}$ below the water surface. The mice were trained to find the hidden platform for 5 consecutive days, four trials of 90 seconds per day. In each trial, the mouse started from one of the four quadrants facing the wall of the pool and ended when the mouse climbed on the platform. If the mice did not find the platform in $90 \mathrm{~s}$, they were guided to the platform. To test reference memory, the platform was removed on day 6 and the percentage of time that the mice spent in each quadrant was recorded. The visible platform tests (with the platform marked) were given on day 7 and day 8 to evaluate sensorimotor abilities and motivation of the animals. Swim paths were recorded on a CCD camera and analyzed using WaterMaze 3 Software. Average swimming speed was determined to exclude motor impairments.

2.6. Statistics Analysis. The values were presented as the mean \pm SEM. Statistical analysis of Western blot was conducted by a one-way analysis of variance followed by all pairwise multiple comparison procedures using the Bonferroni test. The statistical analysis of the Morris water maze was conducted by a two-way analysis of variance followed by all pairwise multiple comparison procedures using the Bonferroni test. All results were regarded as at least $p<0.05$ was considered statistically significant.

\section{Results}

3.1. Biochemical Characteristics of the Mice. At the beginning of the experiment, there was no significant difference among the groups in blood glucose and body weight. Following STZ injection, the mice developed DM rapidly with a mean blood glucose of $13.13 \pm 4.74 \mathrm{mmol} / \mathrm{L}$ on day 3 after STZ injection, $18.87 \pm 3.79 \mathrm{mmol} / \mathrm{L}$ at 2 weeks, and $26.7 \pm 5.70 \mathrm{mmol} / \mathrm{L}$ at 8 weeks (Figure 1(a)). As shown in Figure 1(b), the body weight of the T1DM group increased (from $19.38 \pm 2.03 \mathrm{~g}$ to $26.12 \pm 2.36 \mathrm{~g}$ at 8 weeks after STZ injection) but much more slowly than the increase of the CON group (from $19.18 \pm 1.54 \mathrm{~g}$ to $30.22 \pm 1.43 \mathrm{~g}$ at 8 weeks after STZ injection). There was no significant difference in blood glucose and body weight between the $\mathrm{cPKC} \gamma^{+/+}$diabetic mice and the $\operatorname{scPKC} \gamma^{-l-}$ diabetic mice (Figures $1(\mathrm{a})$ and $1(\mathrm{~b})$ ).

\subsection{Expression of PKC Isoforms in the Hippocampus,} Prefrontal Cortex, and Striatum of the T1DM Mice. In the next set of experiments, we observed whether diabetes mellitus affected the expression patterns of PKC isoforms in the hippocampus, prefrontal cortex, and striatum. As shown in Figures 2 and 3, we observed that the expression of cPKC $\beta \mathrm{II}, \mathrm{nPKC} \varepsilon$, and $\mathrm{cPKC} \gamma$ did not change in the above brain regions at 2 or 8 weeks after STZ injection. These results indicated that chronic T1DM did not affect the expression of the three PKC isoforms in the hippocampus, prefrontal cortex, and striatum.
3.3. Membrane Translocation of PKC Isoforms in the Hippocampus, Prefrontal Cortex, and Striatum of the TIDM Mice. The activation of PKC relates to a transition from the cytosolic autoinhibited form to the membrane-associated active form [27]. To figure out whether PKC isoforms are involved in type 1 diabetic encephalopathy, we observed the membrane translocation of PKC isoforms in the hippocampus, prefrontal cortex, and striatum of the T1DM mice.

As shown in Figures 4(c) and 5(c), chronic T1DM did not affect the membrane translocation of $\mathrm{nPKC} \varepsilon$ in the hippocampus, prefrontal cortex, and striatum at 2 weeks and 8 weeks after STZ injection. The ratio of membranal cPKC $\beta$ II to cytosolic $\mathrm{cPKC} \beta \mathrm{II}$ was not significantly altered in the three brain regions at 2 weeks (Figure 4(a)) but dramatically decreased in the prefrontal cortex and hippocampus at 8 weeks (Figure 5(a)). Moreover, chronic T1DM significantly reduced the ratio of membranal $\mathrm{cPKC} \gamma$ to cytosolic $\mathrm{cPKC} \gamma$ in the hippocampus at 2 weeks (Figure 4(b)) and in the prefrontal cortex, hippocampus, and striatum at 8 weeks (Figure 5(b)).

\subsection{Effects of $c P K C \gamma$ on Spatial Learning and Memory of} Mice. To explore the role of $\mathrm{cPKC} \gamma$ in learning and memory, the Morris water maze test was used at 8 weeks after STZ injection. On day 5 , the diabetic mice had a significantly increased latency to find the hidden platform compared to control mice (Figure 1(c)). Furthermore, the $\mathrm{cPKC}$ deficient diabetic mice took more time to find the hidden platform than the wild-type diabetic mice (Figure 1(c)).

On day 6, swim patterns indicated that control mice swam immediately towards the target area, where the platform used was placed, tried to find the platform, and swam back and forth. In contrast, diabetic mice swam in random circles throughout the pool (Figure 1(e)). In addition, the $\mathrm{CPKC} \gamma^{-1-}$ diabetic mice performed worse than the wildtype diabetic mice (Figure 1(e)).

The percentage of the time spent swimming in the target quadrant (quadrant II) was significantly lower for diabetic mice than for control mice (Figure 1(d)). Moreover, $\mathrm{cPKC} \gamma^{-/-}$diabetic mice spent less time in the target quadrant than $\mathrm{CPKC} \gamma^{+/+}$diabetic mice (Figure 1(d)), again indicating memory impairment in the $\mathrm{CPKC} \gamma$ knockout mice.

As both the vision and sensorimotor abilities of mice could affect the reliability of Morris water maze tests, the visible platform tests (with the platform marked) were given on day 7 and day 8 . There were no significant differences in escape latency among groups (Figure $1(\mathrm{c})$ ). As shown in Figure 1(f), no significant differences in average speed were observed among groups in 8 days. These results suggested that chronic T1DM could induce spatial learning and memory deficits of mice without affecting their visual and sensorimotor abilities and $\mathrm{cPKC} \gamma$ deficiency aggravated the spatial learning and memory impairment of T1DM mice.

\section{Discussion}

Several studies have reported that the expression of $\mathrm{cPKC} \beta \mathrm{II}$, ${ }_{\mathrm{cPKC}} \gamma$, and $\mathrm{nPKC} \varepsilon$ is altered by hyperglycemia. The expression of $\mathrm{cPKC} \beta \mathrm{II}$ increases in the renal tissues of diabetic rats 


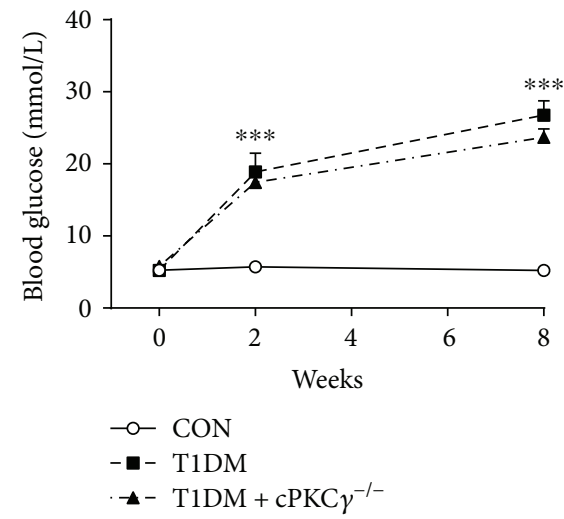

(a)

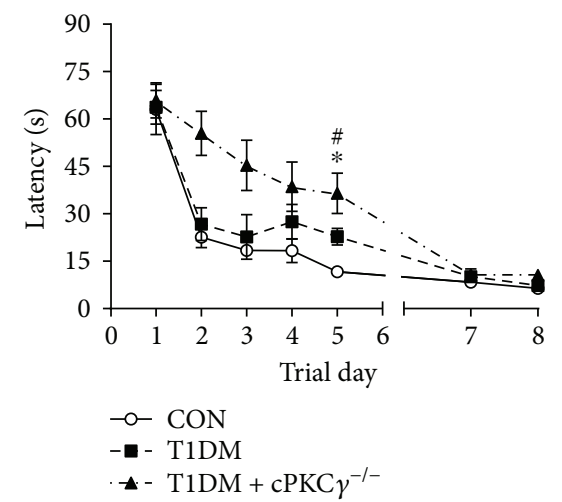

(c)

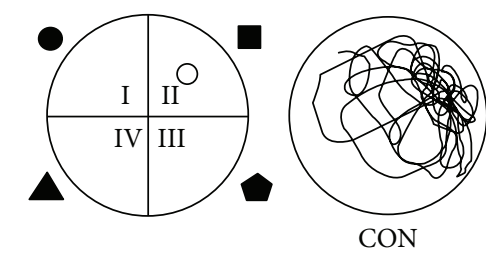

(e)

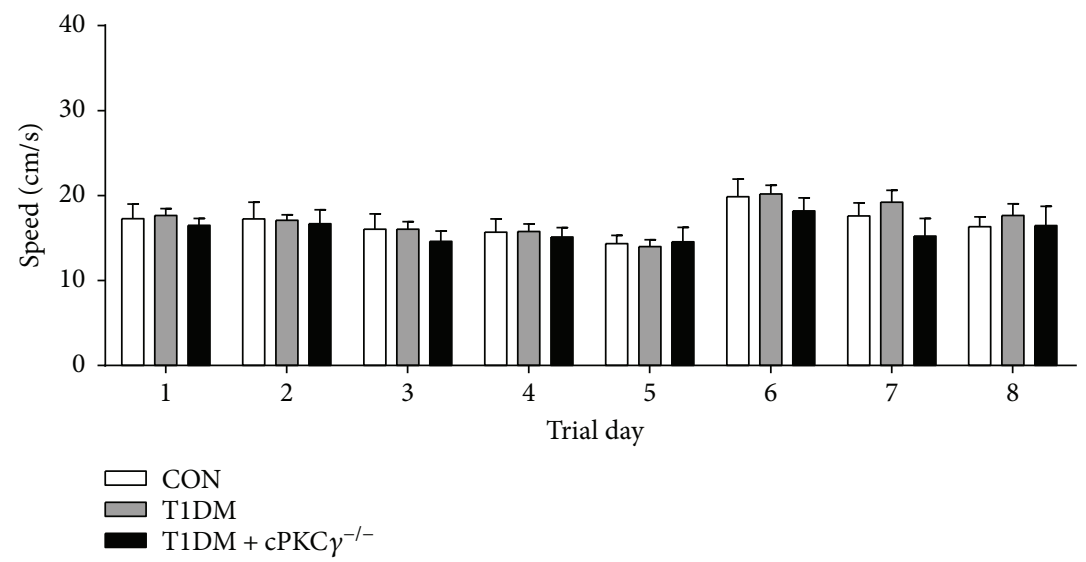

(f)

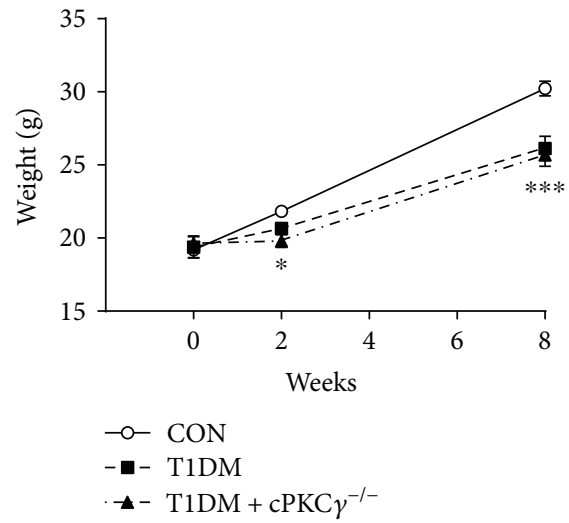

(b)

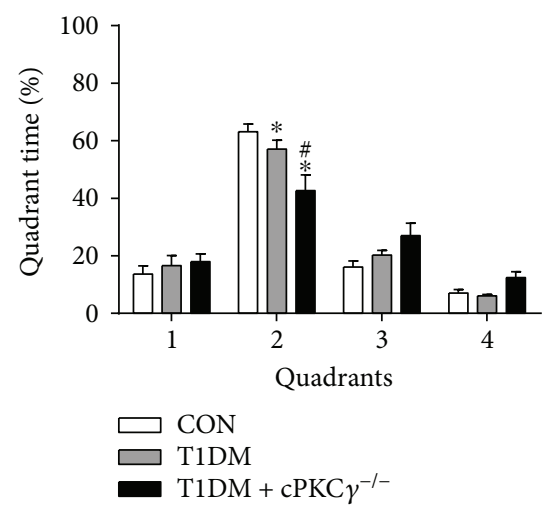

(d)

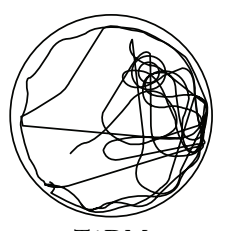

T1DM

$\mathrm{T} 1 \mathrm{DM}+\mathrm{cPKC}^{-/-}$

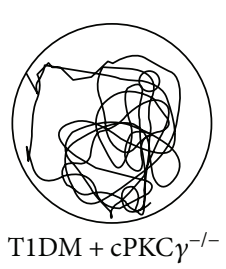



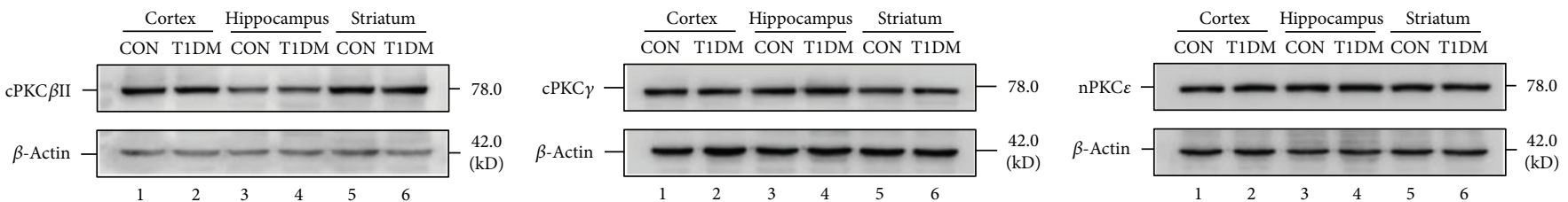

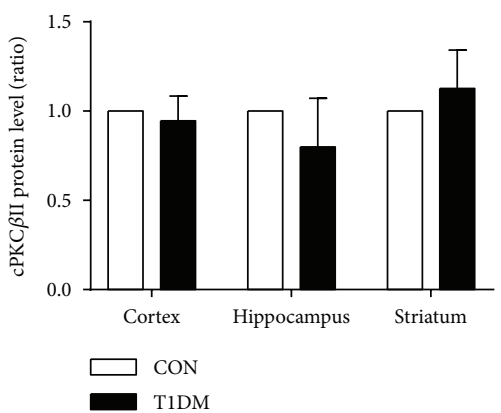

(a)

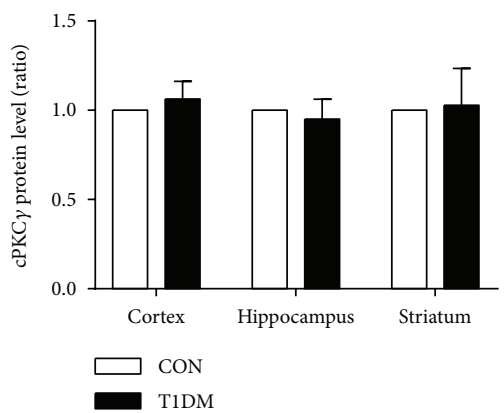

(b)

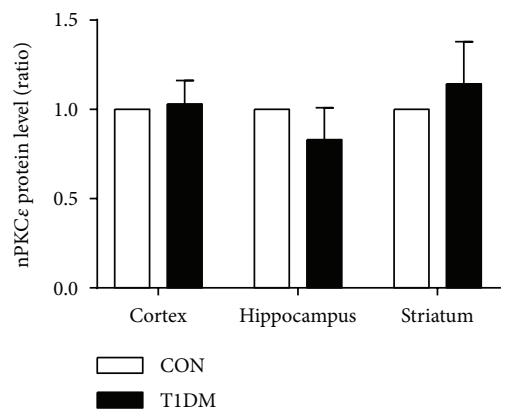

(c)

Figure 2: Expression of PKC isoforms in the cortex, hippocampus, and striatum at 2 weeks after STZ injection. (a) Representative and statistical results of Western blot analysis showed the levels of cPKC $\beta \mathrm{II}$ in the cortex, hippocampus, and striatum at 2 weeks after STZ injection. (b) Representative and statistical results of Western blot analysis showed the levels of cPKC $\gamma$ in the cortex, hippocampus, and striatum at 2 weeks after STZ injection. (c) Representative and statistical results of Western blot analysis showed the levels of nPKCe in the cortex, hippocampus, and striatum at 2 weeks after STZ injection. $n=6$ per group.
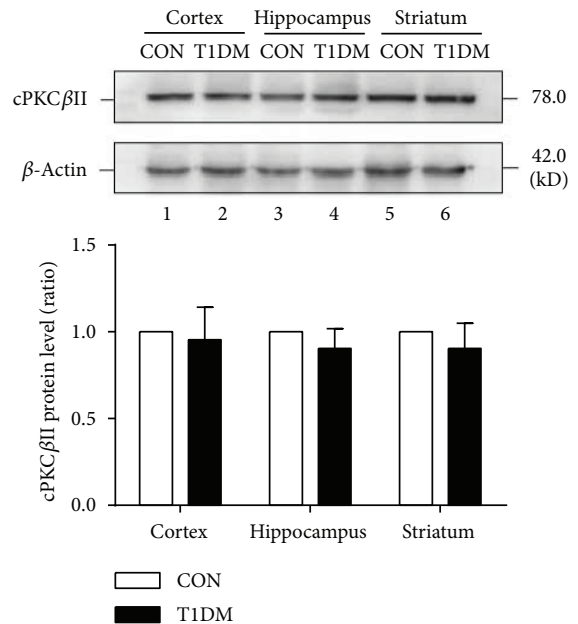

(a)
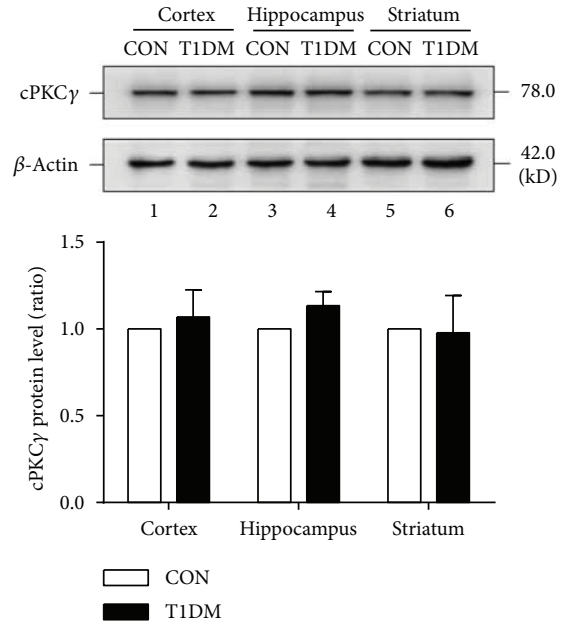

(b)
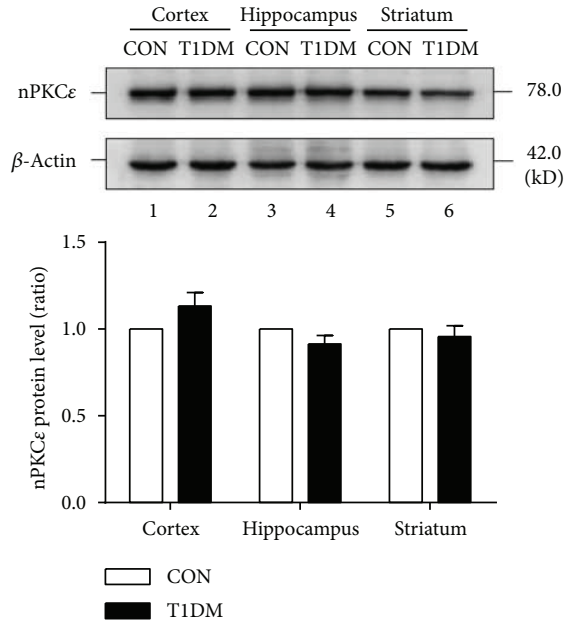

(c)

FIgURE 3: Expression of PKC isoforms in the cortex, hippocampus, and striatum at 8 weeks after STZ injection. (a) Representative and statistical results of Western blot analysis showed the levels of cPKC $\beta \mathrm{II}$ in the cortex, hippocampus, and striatum at 8 weeks after STZ injection. (b) Representative and statistical results of Western blot analysis showed the levels of cPKC $\gamma$ in the cortex, hippocampus, and striatum at 8 weeks after STZ injection. (c) Representative and statistical results of Western blot analysis showed the levels of nPKCe in the cortex, hippocampus, and striatum at 8 weeks after STZ injection. $n=6$ per group.

on 21 days after STZ injection [28]. The nPKCe level increases in the skeletal muscle of nutritionally induced diabetic rats in 3 weeks [29] and vessels of spontaneously diabetic rats [30]. And the expression of $\mathrm{cPKC} \gamma$ is also found to increase in the trigeminal spinal nucleus of T1DM mice on 14 days after STZ injection [21]. Interestingly, the expression of $\mathrm{cPKC} \beta \mathrm{II}, \mathrm{cPKC} \gamma$, and $\mathrm{nPKC} \varepsilon$ may not change in the cerebral cortex, but the levels of $\mathrm{cPKC} \gamma$ and $\mathrm{nPKC} \varepsilon$ are decreased in the glio-pial tissue of T1DM rats at 16 weeks after STZ injection [31]. In this study, we explored the expression and activation of $\mathrm{cPKC} \beta \mathrm{II}, \mathrm{cPKC} \gamma$, and $\mathrm{nPKC} \varepsilon$ in the hippocampus, prefrontal cortex, and striatum, the regions important in the cognitive processes of learning, memory, and decision-making [32-34]. We observed that T1DM did not significantly change the protein expression of $\mathrm{cPKC} \beta \mathrm{II}, \mathrm{cPKC} \gamma$, and $\mathrm{nPKC} \varepsilon$ in the three brain regions at 2 weeks after STZ injection. Next, we prolonged the observation time. But we still did not find significant changes in the protein expression of $\mathrm{cPKC} \beta \mathrm{II}, \mathrm{cPKC} \gamma$, and $\mathrm{nPKC} \varepsilon$ at 8 weeks after STZ injection. 


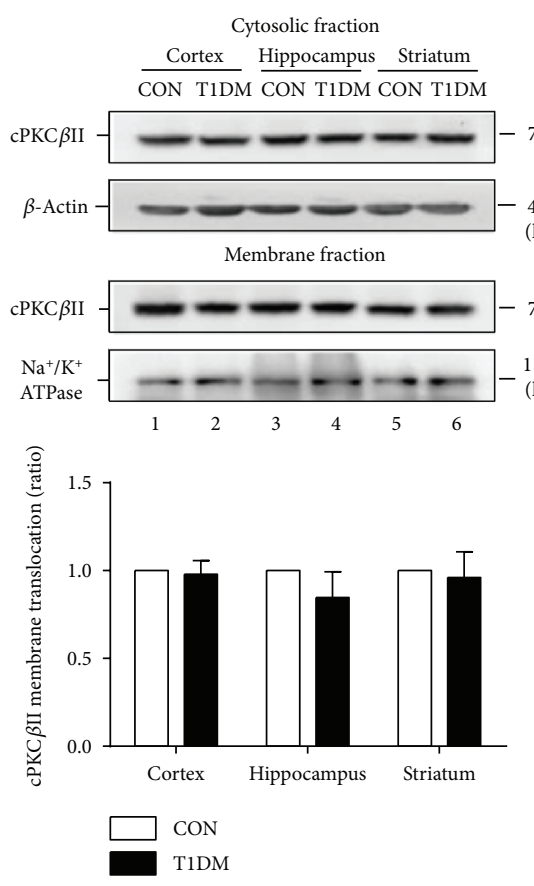

(a)
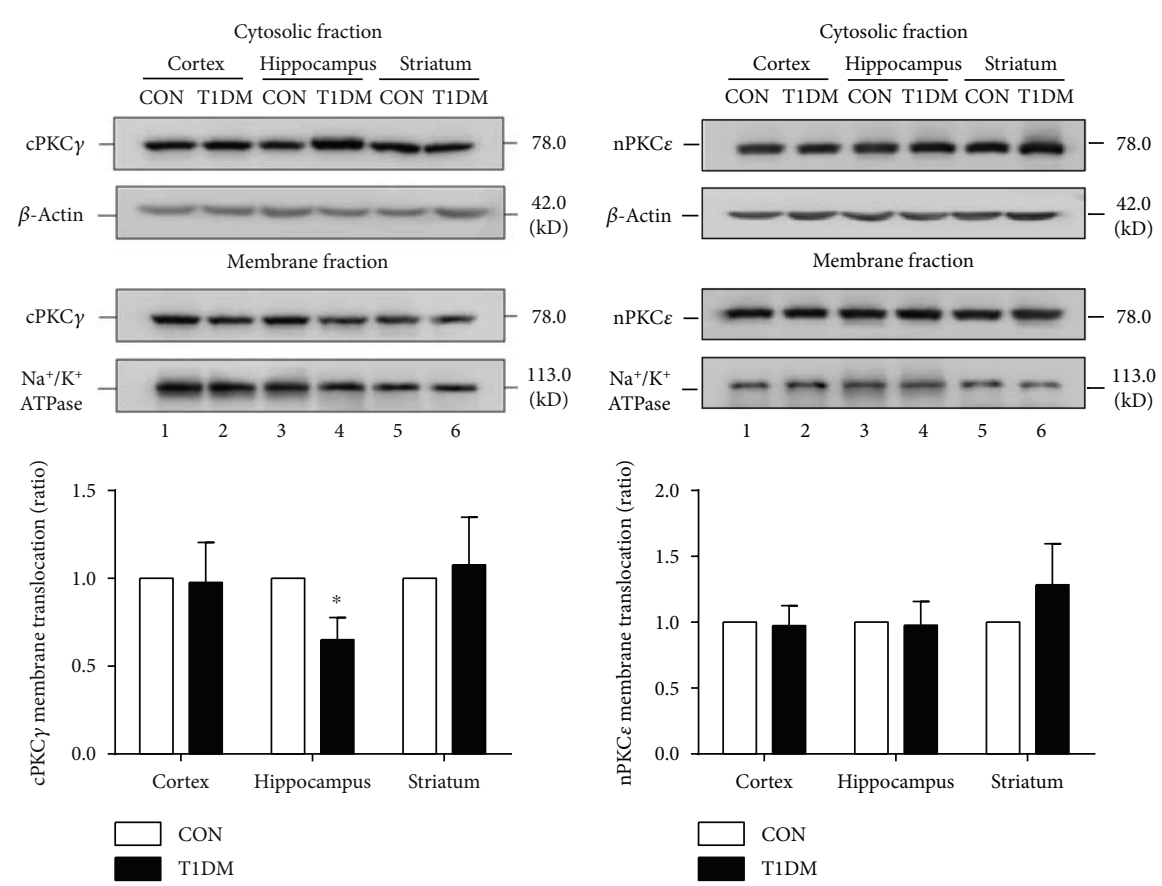

(b)

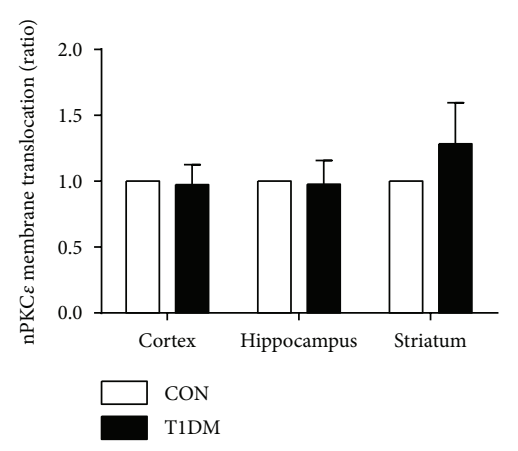

(c)

FIgURE 4: Membrane translocation of PKC isoforms in the cortex, hippocampus, and striatum at 2 weeks after STZ injection. (a) Representative and statistical results of Western blot analysis showed the membrane translocation of cPKC $\beta$ II in the cortex, hippocampus, and striatum at 2 weeks after STZ injection. (b) Representative and statistical results of Western blot analysis showed the membrane translocation of $\mathrm{cPKC} \gamma$ in the cortex, hippocampus, and striatum at 2 weeks after STZ injection. (c) Representative and statistical results of Western blot analysis showed the membrane translocation of $\mathrm{nPKC} \varepsilon$ in the cortex, hippocampus, and striatum at 2 weeks after STZ injection. ${ }^{*} p<0.05$ compared with the CON group. $n=6$ per group.

Activation of PKC is associated with the translocation of enzymes from the cytosol to the membrane. The membrane translocation or activation of PKC isoforms is linked to the development of pathologies in diabetes. The acute blood glucose fluctuation significantly increased cPKC $\beta \mathrm{II}$ membrane translocation, which causes the apoptosis of vascular endothelial cell through increasing oxidative stress and induces impairment of insulin signaling in diabetic rats [11]. Activation of cPKC $\beta$ II by hyperglycemia upregulates caspase 8-induced apoptosis in blood-brain barrier endothelial cells [35]. Activation of $\mathrm{nPKCE}$, as a result of the accumulation of diacylglycerol, results in hepatic insulin resistance and nonalcoholic fatty liver disease in patients and type 2 diabetic mice $[19,36]$. Activation of $\mathrm{cPKC} \gamma$ by early STZ-induced diabetes causes the inhibition of lens gap junction activity in rats [37]. In this study, we found that T1DM mice exhibited spatial learning and memory impairment in the Morris water maze at 8 weeks after STZ injection. Meanwhile, T1DM failed to affect $\mathrm{nPKC} \varepsilon$ membrane translocation in the hippocampus, prefrontal cortex, and striatum at 8 weeks. However, the translocation of $\mathrm{cPKC} \beta \mathrm{II}$ and $\mathrm{cPKC} \gamma$ from the cytosol to the membrane was significantly decreased in the brain of T1DM mice at 8 weeks, indicating that they might be involved in type 1 diabetic encephalopathy.

It is well accepted that $\mathrm{cPKC} \beta \mathrm{II}$ is essential for learning and memory formation $[38,39]$. The downregulation of cPKC $\beta I I$ in the hippocampus of offspring, especially in the CA3, CA1, and dentate gyrus, the regions important in the entorhinal-hippocampal trisynaptic circuit, is responsible for impaired learning and memory of prenatally stressed offspring [40]. The levels of cPKC $\beta$ II decrease in the striatum and cortex of transgenic Huntington's disease mice, which is associated with impaired information storage and memory disorder [41]. The baseline asymmetry and lateralized changes of $\mathrm{CPKC} \beta \mathrm{II}$ in the rat amygdale are associated with the cue and context in a classical fear conditioning paradigm [42]. And furthermore, the cPKC $\beta \mathrm{II}$ knockout mice also exhibit a loss of learning and suffer deficits in both cued and contextual fear conditioning [43].

${ }_{\mathrm{cPKC}} \gamma$ is a neuron-specific isoform, and its activity is suggested to be related to spatial memory in aged rats $[44,45]$. Activation of $\mathrm{cPKC} \gamma$ in the CA1 region participates in postsynaptic plasticity associated with spatial experiences and learning [46]. Young rats, those with the best spatial memory, are those with the highest concentrations of cPKC $\gamma$ in the particulate fraction. Conversely, aged rats with poor spatial memory increase hippocampal cPKC $\gamma$ concentrations in soluble fraction in comparison with young rats, which indicates that the decrease in $\mathrm{cPKC} \gamma$ activity is correlated with memory impairment [47]. In addition, $\mathrm{CPKC} \gamma$ is found to participate in the reversal of learning and memory deficits by intranasal insulin treatment in $\mathrm{AD}$ mice [48]. In this study, we found that the decrease in $\mathrm{cPKC} \gamma$ activity induced by T1DM came earlier and occurred in more brain regions than $\mathrm{CPKC} \beta \mathrm{II}$, suggesting that $\mathrm{CPKC} \gamma$ played a bigger role in the diabetic encephalopathy. Therefore, we deleted the 


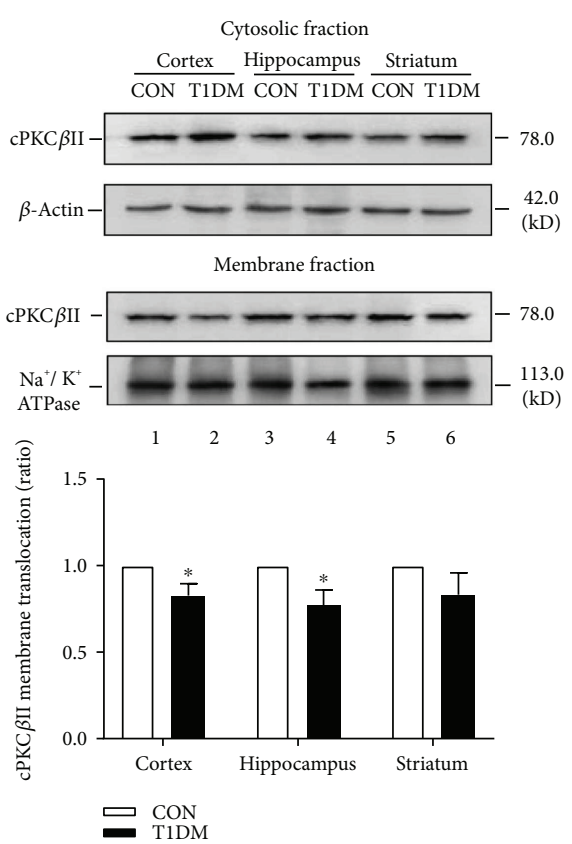

(a)

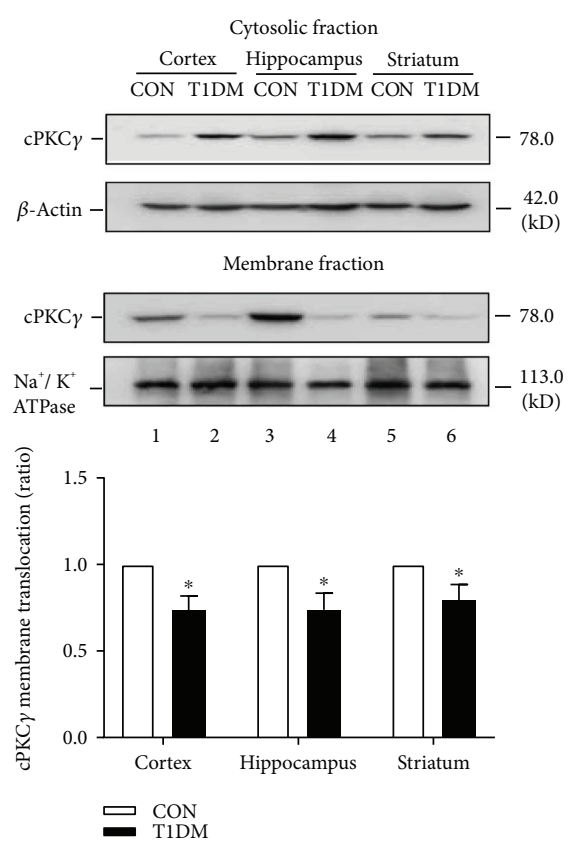

(b)

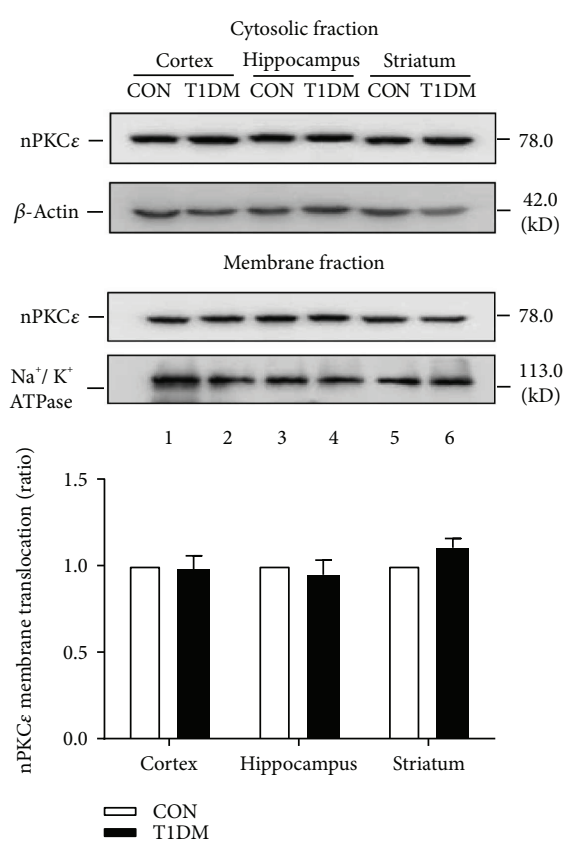

(c)

FIGURE 5: Membrane translocation of PKC isoforms in the cortex, hippocampus, and striatum at 8 weeks after STZ injection. (a) Representative and statistical results of Western blot analysis showed the membrane translocation of $\mathrm{CPKC} \beta \mathrm{II}$ in the cortex, hippocampus, and striatum at 8 weeks after STZ injection. (b) Representative and statistical results of Western blot analysis showed the membrane translocation of $\mathrm{cPKC} \gamma$ in the cortex, hippocampus, and striatum at 8 weeks after STZ injection. (c) Representative and statistical results of Western blot analysis showed the membrane translocation of $\mathrm{nPKC} \varepsilon$ in the cortex, hippocampus, and striatum at 8 weeks after STZ injection. ${ }^{*} p<0.05$ compared with the CON group. $n=6$ per group.

cPKC $\gamma$ gene in mice and then found that the spatial learning and memory of $\mathrm{cPKC} \gamma^{-/-}$diabetic mice are worse than those of wild diabetic mice.

Elevated glucose level and impaired glucose tolerance can affect the spatial learning and memory, which is associated with hippocampal apoptosis [49-52]. But in this study, we found that $\mathrm{cPKC} \gamma$ did not affect blood glucose level, demonstrating that the effect of cPKC $\gamma$ on cognitive function is irrelevant to blood glucose. PKC activators have been reported to improve cognitive function by restoring PKC signaling and downstream activity, including stimulation of synaptic plasticity and development [53], reduction in accumulation of neurotoxic amyloid $\beta$, regulation of tau protein hyperphosphorylation [38], and support of antiapoptotic processes [54]. Further studies about the mechanism how $\mathrm{CPKC} \gamma$ can enhance spatial memory performance in T1DM mice are required.

\section{Conclusion}

Our results indicate that the activation of $\mathrm{cPKC} \beta \mathrm{II}$ and ${ }_{\mathrm{cPKC}} \gamma$, not $\mathrm{nPKC} \varepsilon$, may be involved in the development of the diabetic encephalopathy in mice. $\mathrm{cPKC} \gamma$ can dramatically improve learning and memory performances impaired by diabetes mellitus in mice.

\section{Conflicts of Interest}

The authors declare that there are no conflicts of interest.

\section{Authors' Contributions}

Li Zhao and Junfa Li designed the experiments. Jiayin Zheng, Yue Wang, Song Han, Xiuli Sun, and Ning Zhu performed the experiments. Jiayin Zheng and Yanlin Luo analyzed the data. Jiayin Zheng and Yue Wang wrote the paper. Li Zhao, Yue Wang, and Junfa Li revised the paper. Jiayin Zheng and Yue Wang contributed equally to this work.

\section{Acknowledgments}

The authors disclosed the receipt of the following financial support for the research, authorship, and/or publication of this article: National Natural Science Foundation of China (Grant nos. 81400948, 31671205, and 31471142) and Beijing Natural Science Foundation (Grant no. 7141001).

\section{References}

[1] World Health Organization, Global Report on Diabetes, World Health Organization, Geneva, 2016.

[2] B. Kim, C. Backus, S. Oh, and E. L. Feldman, "Hyperglycemiainduced tau cleavage in vitro and in vivo: a possible link between diabetes and Alzheimer's disease," Journal of Alzheimer's Disease, vol. 34, no. 3, pp. 727-739, 2013.

[3] N. Mukai, T. Ohara, J. Hata et al., "Alternative measures of hyperglycemia and risk of Alzheimer's disease in the community: the Hisayama study," The Journal of Clinical Endocrinology and Metabolism, vol. 102, no. 8, pp. 3002-3010, 2017. 
[4] J. Q. Wang, J. Yin, Y. F. Song et al., "Brain aging and AD-like pathology in streptozotocin-induced diabetic rats," Journal of Diabetes Research, vol. 2014, Article ID 796840, 12 pages, 2014.

[5] C. G. Jolivalt, R. Hurford, C. A. Lee, W. Dumaop, E. Rockenstein, and E. Masliah, "Type 1 diabetes exaggerates features of Alzheimer's disease in APP transgenic mice," Experimental Neurology, vol. 223, no. 2, pp. 422-431, 2010.

[6] C. G. Jolivalt, C. A. Lee, K. K. Beiswenger et al., "Defective insulin signaling pathway and increased glycogen synthase kinase-3 activity in the brain of diabetic mice: parallels with Alzheimer's disease and correction by insulin," Journal of Neuroscience Research, vol. 86, no. 15, pp. 3265-3274, 2008.

[7] G. S. Mijnhout, P. Scheltens, M. Diamant et al., "Diabetic encephalopathy: a concept in need of a definition," Diabetologia, vol. 49, no. 6, pp. 1447-1448, 2006.

[8] S. Samarghandian, M. Azimi-Nezhad, and F. Samini, "Ameliorative effect of saffron aqueous extract on hyperglycemia, hyperlipidemia, and oxidative stress on diabetic encephalopathy in streptozotocin induced experimental diabetes mellitus," BioMed Research International, vol. 2014, Article ID 920857, 12 pages, 2014.

[9] M. Brownlee, "The pathobiology of diabetic complications: a unifying mechanism," Diabetes, vol. 54, no. 6, pp. 16151625, 2005.

[10] F. Vetri, M. Qi, H. Xu, J. Oberholzer, and C. Paisansathan, "Impairment of neurovascular coupling in type 1 diabetes mellitus in rats is prevented by pancreatic islet transplantation and reversed by a semi-selective PKC inhibitor," Brain Research, vol. 1655, pp. 48-54, 2017.

[11] N. Wu, H. Shen, Y. Wang et al., "Role of the PKC $\beta I I / J N K$ signaling pathway in acute glucose fluctuation-induced apoptosis of rat vascular endothelial cells," Acta Diabetologica, vol. 54, no. 8, pp. 727-736, 2017.

[12] B. Capuani, F. Pacifici, D. Pastore et al., "The role of epsilon PKC in acute and chronic diseases: possible pharmacological implications of its modulators," Pharmacological Research, vol. 111, pp. 659-667, 2016.

[13] A. M. Kay, C. L. Simpson, and J. A. Stewart Jr., “The Role of AGE/RAGE signaling in diabetes-mediated vascular calcification," Journal of Diabetes Research, vol. 2016, Article ID 6809703, 8 pages, 2016.

[14] M. C. Perez-Matos, M. C. Morales-Alvarez, and C. O. Mendivil, "Lipids: a suitable therapeutic target in diabetic neuropathy?," Journal of Diabetes Research, vol. 2017, Article ID 6943851, 9 pages, 2017.

[15] V. Thallas-Bonke and M. E. Cooper, "Tandem inhibition of PKC in $\operatorname{di} \alpha \beta$ etic nephropathy: it takes two to tango?," Diabetes, vol. 62, no. 4, pp. 1010-1011, 2013.

[16] A. S. Al-Onazi, N. M. Al-Rasheed, H. A. Attia et al., "Ruboxistaurin attenuates diabetic nephropathy via modulation of TGF- $\beta 1 /$ Smad and GRAP pathways," The Journal of Pharmacy and Pharmacology, vol. 68, no. 2, pp. 219-232, 2016.

[17] M. Amadio, C. Bucolo, G. M. Leggio, F. Drago, S. Govoni, and A. Pascale, "The PKC $\beta /$ HuR/VEGF pathway in diabetic retinopathy," Biochemical Pharmacology, vol. 80, no. 8, pp. 1230-1237, 2010.

[18] V. T. Samuel, Z. X. Liu, A. Wang et al., "Inhibition of protein kinase $\mathrm{C} \varepsilon$ prevents hepatic insulin resistance in nonalcoholic fatty liver disease," The Journal of Clinical Investigation, vol. 117, no. 3, pp. 739-745, 2007.
[19] A. L. Birkenfeld and G. I. Shulman, "Nonalcoholic fatty liver disease, hepatic insulin resistance, and type 2 diabetes," Нераtology, vol. 59, no. 2, pp. 713-723, 2014.

[20] J. Cantley, J. G. Burchfield, G. L. Pearson, C. Schmitz-Peiffer, M. Leitges, and T. J. Biden, "Deletion of PKCe selectively enhances the amplifying pathways of glucose-stimulated insulin secretion via increased lipolysis in mouse $\beta$-cells," Diabetes, vol. 58, no. 8, pp. 1826-1834, 2009.

[21] H. Y. Xie, F. Xu, Y. Li et al., "Increases in PKC gamma expression in trigeminal spinal nucleus is associated with orofacial thermal hyperalgesia in streptozotocin-induced diabetic mice," Journal of Chemical Neuroanatomy, vol. 63, pp. 1319, 2015.

[22] M. Gareskog and P. Wentzel, "Altered protein kinase C activation associated with rat embryonic dysmorphogenesis," Pediatric Research, vol. 56, no. 6, pp. 849-857, 2004.

[23] X. Tian, Y. Liu, G. Ren et al., "Resveratrol limits diabetesassociated cognitive decline in rats by preventing oxidative stress and inflammation and modulating hippocampal structural synaptic plasticity," Brain Research, vol. 1650, pp. 19, 2016

[24] J. Li, Y. Qu, P. Zu et al., "Increased isoform-specific membrane translocation of conventional and novel protein kinase $\mathrm{C}$ in human neuroblastoma SH-SY5Y cells following prolonged hypoxia," Brain Research, vol. 1093, no. 1, pp. 25-32, 2006.

[25] L. Zhao, X. Liu, J. Liang et al., "Phosphorylation of p38 MAPK mediates hypoxic preconditioning-induced neuroprotection against cerebral ischemic injury via mitochondria translocation of Bcl-xL in mice," Brain Research, vol. 1503, pp. 78-88, 2013.

[26] D. Zhang, S. Han, S. Wang, Y. Luo, L. Zhao, and J. Li, "cPKC $\gamma$ mediated down-regulation of UCHL1 alleviates ischaemic neuronal injuries by decreasing autophagy via ERK-mTOR pathway," Journal of Cellular and Molecular Medicine, vol. 21, no. 12, pp. 3641-3657, 2017.

[27] T. I. Igumenova, "Dynamics and membrane interactions of protein kinase C," Biochemistry, vol. 54, no. 32, pp. 49534968, 2015.

[28] E. Molina-Jijón, R. Rodríguez-Muñoz, M. del Carmen Namorado et al., "All-trans retinoic acid prevents oxidative stress-induced loss of renal tight junction proteins in type-1 diabetic model," The Journal of Nutritional Biochemistry, vol. 26, no. 5, pp. 441-454, 2015.

[29] Y. Ikeda, G. S. Olsen, E. Ziv et al., "Cellular mechanism of nutritionally induced insulin resistance in Psammomys obesus: overexpression of protein kinase $\mathrm{C} \varepsilon$ in skeletal muscle precedes the onset of hyperinsulinemia and hyperglycemia," Diabetes, vol. 50, no. 3, pp. 584-592, 2001.

[30] J. Radosinska, L. H. Kurahara, K. Hiraishi et al., "Modulation of cardiac connexin- 43 by omega- 3 fatty acid ethyl-ester supplementation demonstrated in spontaneously diabetic rats," Physiological Research, vol. 64, no. 6, pp. 795-806, 2015.

[31] F. Vetri, R. Chavez, H. L. Xu, C. Paisansathan, and D. A. Pelligrino, "Complex modulation of the expression of PKC isoforms in the rat brain during chronic type 1 diabetes mellitus," Brain Research, vol. 1490, pp. 202-209, 2013.

[32] J. D. Shin and S. P. Jadhav, "Multiple modes of hippocampalprefrontal interactions in memory-guided behavior," Current Opinion in Neurobiology, vol. 40, pp. 161-169, 2016.

[33] O. Y. Chao, S. Nikolaus, M. Lira Brandao, J. P. Huston, and M. A. de Souza Silva, "Interaction between the medial 
prefrontal cortex and hippocampal CA1 area is essential for episodic-like memory in rats," Neurobiology of Learning and Memory, vol. 141, pp. 72-77, 2017.

[34] M. Mendez-Couz, N. M. Conejo, H. Gonzalez-Pardo, and J. L. Arias, "Functional interactions between dentate gyrus, striatum and anterior thalamic nuclei on spatial memory retrieval," Brain Research, vol. 1605, pp. 59-69, 2015.

[35] Y. Cao, Z. Zhao, R. L. Eckert, and E. A. Reece, "Protein kinase $\mathrm{C} \beta 2$ inhibition reduces hyperglycemia-induced neural tube defects through suppression of a caspase 8-triggered apoptotic pathway," American Journal of Obstetrics and Gynecology, vol. 204, no. 3, pp. 226.e1-226.e5, 2011.

[36] M. C. Petersen, A. K. Madiraju, B. M. Gassaway et al., "Insulin receptor Thr1160 phosphorylation mediates lipid-induced hepatic insulin resistance," The Journal of Clinical Investigation, vol. 126, no. 11, pp. 4361-4371, 2016.

[37] D. Lin, R. Harris, R. Stutzman, G. A. Zampighi, H. Davidson, and D. J. Takemoto, "Protein kinase C- $\gamma$ activation in the early streptozotocin diabetic rat lens," Current Eye Research, vol. 32, no. 6, pp. 523-532, 2007.

[38] B. P. Lucke-Wold, R. C. Turner, A. F. Logsdon et al., "Common mechanisms of Alzheimer's disease and ischemic stroke: the role of protein kinase $\mathrm{C}$ in the progression of agerelated neurodegeneration," Journal of Alzheimer's Disease, vol. 43, no. 3, pp. 711-724, 2015.

[39] A. Olariu, K. Yamada, T. Mamiya, V. Hefco, and T. Nabeshima, "Memory impairment induced by chronic intracerebroventricular infusion of beta-amyloid (1-40) involves downregulation of protein kinase C," Brain Research, vol. 957, no. 2, pp. 278-286, 2002.

[40] J. Wu, T. B. Song, Y. J. Li, K. S. He, L. Ge, and L. R. Wang, "Prenatal restraint stress impairs learning and memory and hippocampal PKCbetal expression and translocation in offspring rats," Brain Research, vol. 1141, pp. 205-213, 2007.

[41] A. S. Harris, E. M. Denovan-Wright, L. C. Hamilton, and H. A. Robertson, "Protein kinase C beta II mRNA levels decrease in the striatum and cortex of transgenic Huntington's disease mice," Journal of Psychiatry \& Neuroscience, vol. 26, no. 2, pp. 117-122, 2001.

[42] R. Orman and M. Stewart, "Hemispheric differences in protein kinase C $\beta$ II levels in the rat amygdala: baseline asymmetry and lateralized changes associated with cue and context in a classical fear conditioning paradigm," Neuroscience, vol. 144, no. 3, pp. 797-807, 2007.

[43] E. J. Weeber, C. M. Atkins, J. C. Selcher et al., "A role for the $\beta$ isoform of protein kinase $\mathrm{C}$ in fear conditioning," The Journal of Neuroscience, vol. 20, no. 16, pp. 5906-5914, 2000.

[44] M. A. Rossi, D. C. Mash, and L. deToledo-Morrell, "Spatial memory in aged rats is related to $\mathrm{PKC} \gamma$-dependent Gprotein coupling of the M1 receptor," Neurobiology of Aging, vol. 26, no. 1, pp. 53-68, 2005.

[45] L. Li, L. You, B. Sunyer et al., "Hippocampal protein kinase C family members in spatial memory retrieval in the mouse," Behavioural Brain Research, vol. 258, pp. 202-207, 2014.

[46] J. Nithianantharajah and M. Murphy, "Experience on the Barnes spatial maze influences PKC $\gamma$ levels in the hippocampus," The International Journal of Neuroscience, vol. 119, no. 7, pp. 1014-1030, 2009.

[47] P. J. Colombo, W. C. Wetsel, and M. Gallagher, "Spatial memory is related to hippocampal subcellular concentrations of calcium-dependent protein kinase $\mathrm{C}$ isoforms in young and aged rats," Proceedings of the National Academy of Sciences of the United States of America, vol. 94, no. 25, pp. 1419514199, 1997.

[48] T. S. Salameh, K. M. Bullock, I. A. Hujoel et al., "Central nervous system delivery of intranasal insulin: mechanisms of uptake and effects on cognition," Journal of Alzheimer's Disease, vol. 47, no. 3, pp. 715-728, 2015.

[49] H. Kuang, M. Sun, J. Lv et al., "Hippocampal apoptosis involved in learning deficits in the offspring exposed to maternal high sucrose diets," The Journal of Nutritional Biochemistry, vol. 25, no. 9, pp. 985-990, 2014.

[50] Y. Kohara, S. Kawaguchi, R. Kuwahara, Y. Uchida, Y. Oku, and K. Yamashita, "Genistein improves spatial learning and memory in male rats with elevated glucose level during memory consolidation," Physiology \& Behavior, vol. 140, pp. 15-22, 2015.

[51] S. S. Patel, V. Mehta, H. Changotra, and M. Udayabanu, "Depression mediates impaired glucose tolerance and cognitive dysfunction: a neuromodulatory role of rosiglitazone," Hormones and Behavior, vol. 78, pp. 200-210, 2016.

[52] R. Codella, S. Benedini, S. Paini et al., "Effect of sugar versus mixed breakfast on metabolic and neurofunctional responses in healthy individuals," Journal of Diabetes Research, vol. 2017, Article ID 9634585, 10 pages, 2017.

[53] S. A. Patten and D. W. Ali, "PKC $\gamma$-induced trafficking of AMPA receptors in embryonic zebrafish depends on NSF and PICK1," Proceedings of the National Academy of Sciences of the United States of America, vol. 106, no. 16, pp. 67966801, 2009.

[54] M. K. Sun and D. L. Alkon, "Activation of protein kinase C isozymes for the treatment of dementias," Advances in Pharmacology, vol. 64, pp. 273-302, 2012. 


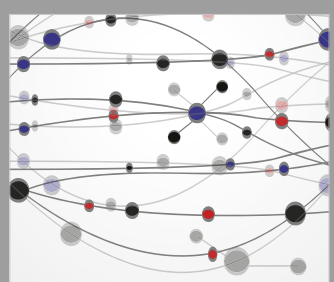

The Scientific World Journal
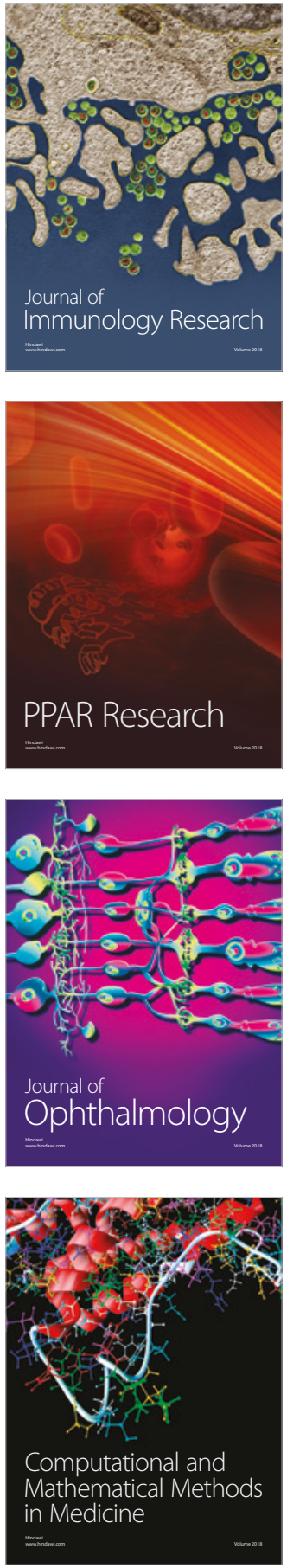

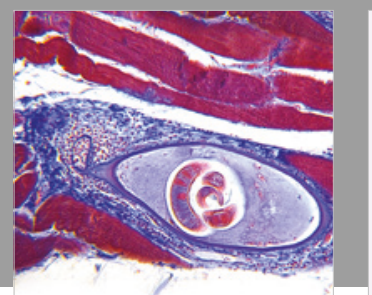

Gastroenterology Research and Practice

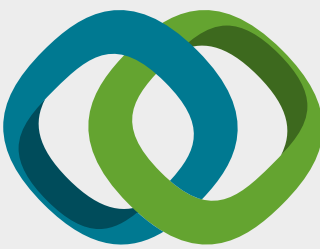

\section{Hindawi}

Submit your manuscripts at

www.hindawi.com
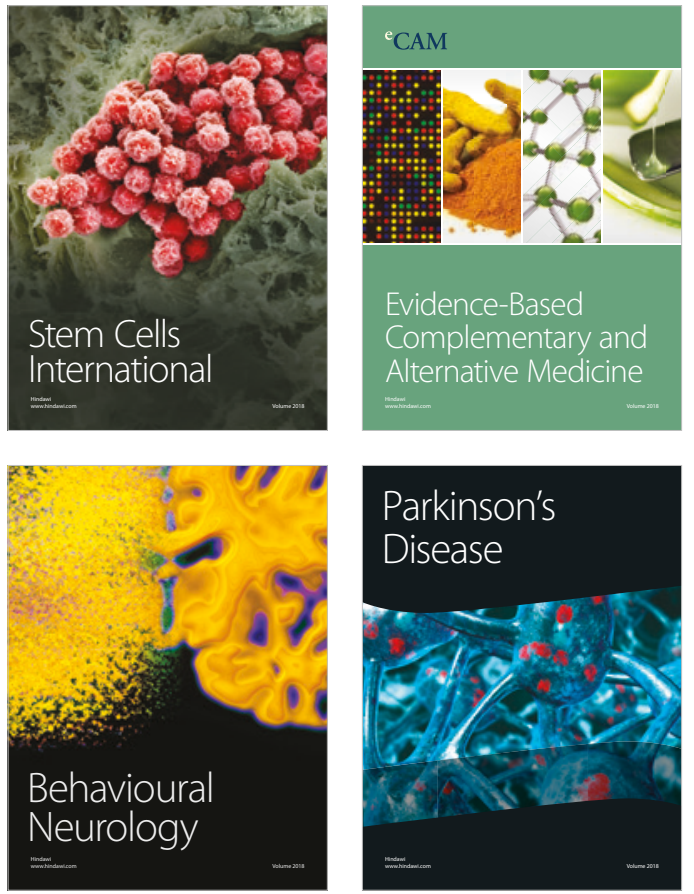

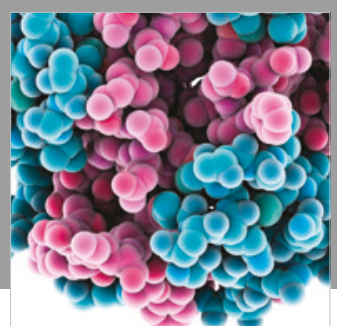

ournal of

Diabetes Research

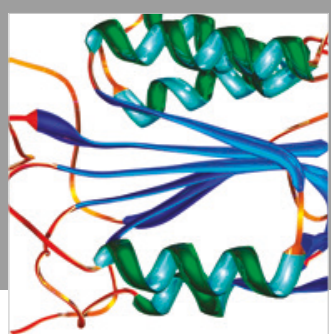

Disease Markers
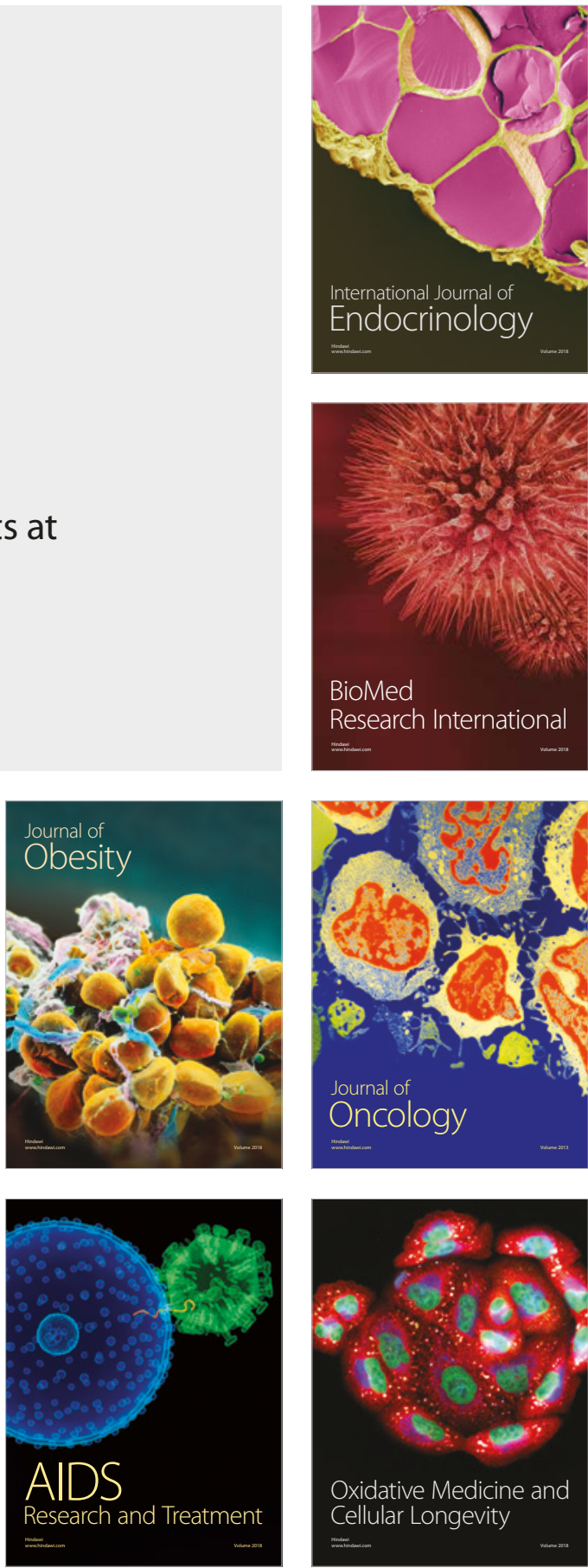